\title{
Translocation of cellular prion protein to non-lipid rafts protects human prion-mediated neuronal damage
}

\author{
JAE-KYO JEONG, MYUNG-HEE MOON, YOU-JIN LEE, JAE-WON SEOL and SANG-YOUEL PARK
}

\begin{abstract}
Korea Zoonoses Research Institute, Center for Healthcare Technology Development, College of Veterinary Medicine, Chonbuk National University, Jeonju, Jeonbuk 561-756, Republic of Korea
\end{abstract}

Received September 29, 2011; Accepted November 1, 2011

DOI: $10.3892 / \mathrm{ijmm} .2011 .864$

\begin{abstract}
Prions are the causative agents of transmissible spongiform encephalopathies, such as variant Creutzfeldt-Jakob disease in humans. Cellular prion proteins (PrPC) connect with cholesterol- and glycosphingolipid-rich lipid rafts through association of their glycosyl-phosphatidylinositol (GPI) anchor with saturated raft lipids and interaction of their N-terminal regions. Our previous study showed that cellular cholesterol enrichment prevented $\operatorname{PrP}(106-126)$-induced neuronal death. We have now studied the influence of membrane cholesterol in $\operatorname{PrP}(106-126)$-mediated neurotoxicity and identified membrane domains involved in this activity. We found that PrPC is normally distributed in lipid rafts, but high membrane cholesterol levels as a result of cholesterol treatment led to the translocation of PrPC from lipid rafts to non-lipid rafts. Moreover, cholesterol-mediated PrPC translocation protects PrP(106-126)-mediated apoptosis and p-38 activation and caspase-3 activation. In a mitochondrial functional assay including mitochondrial transmembrane potential, cholesterol treatment prevented the loss of mitochondrial potential, translocation of Bax and cytochrome c by prion protein fragment. Our results indicate that modulation of the PrPC location appears to protect against neuronal cell death caused by prion peptides. The results of this study suggest that regulation of membrane cholesterol affects the translocation of PrPC, which in turn regulates $\operatorname{PrP}(106-126)$-induced mitochondrial dysfunction and neurotoxicity.
\end{abstract}

\section{Introduction}

Prion diseases are a family of neurodegenerative disorders, affecting humans and animals, characterized by central nervous system (CNS) spongiosis, vacuolation, and neuronal

Correspondence to: Professor Sang-Youel Park, College of Veterinary Medicine, Chonbuk National University, Jeonju, Jeonbuk 561-756, Republic of Korea

E-mail: sypark@chonbuk.ac.kr

Key words: lipid rafts, $\operatorname{PrP}(106-126)$, membrane cholesterol enrichment, neurotoxicity loss (1). The main characteristic associated with the pathogenesis of prion diseases is accumulation of scrapie prion proteins (PrPSc), which are abnormally folded isoforms of normal cellular prion proteins (PrPC) (2). PrPSc are derived from $\mathrm{PrPC}$ as a result of conformational changes in the plasma membranes of neurons $(1,3,4)$.

The PrPC, glycosylphosphatidylinositol (GPI)-anchored cell-surface proteins, are mainly expressed on the cell surface of neurons (5). GPI-anchored PrPC are expressed in cholesterol and sphingolipid-rich membrane microdomains, including lipid rafts and caveolae $(6,7)$. Some reports suggest that the conversion of PrPC to PrPSc takes place in lipid microdomains (8). Indeed, PrPC depletion in neurons could prevent PrPsc accumulation and prion disease development (9). In addition, neurons from GPI-anchorless-prion-expressing transgenic mice are not susceptible to PrPSc (8). The presence of GPI-anchored-PrPC in lipid microdomains, thus, is necessary for the progression of prion diseases and for the replication of PrPSc within the CNS.

Although the mechanism of PrPSc-mediated neurodegeneration is unclear, recent studies suggest that PrPSc induce neuronal cell death via a mitochondrial disruption pathway dependent on cell surface expression of PrPC and employment of a PrPC-caveolin-Fyn signaling pathway $(10,11)$. Indeed, in vivo studies demonstrated induction of neurotoxicity in scrapie-infected mice through activation of mitochondrial apoptosis pathways (12). In addition, $\operatorname{PrP}(106-126)$-mediated mitochondrial disruption was blocked by depletion of PrPC expression and enhanced by the PrPC/caveolin-1/Fyn signaling response in the fully-functional serotonergic $1 \mathrm{C} 11^{5-\mathrm{HT}}$ and noradrenergic $1 \mathrm{C} 11^{\mathrm{NE}}$ cells (10). It is currently suspected that prion pathology involves activation of a mitochondrial apoptotic pathway, as a result of the conversion of PrPC to PrPSc in lipid microdomains.

The synthetic PrP(106-126) contains the amino acid residues 106-126 of PrPC and possesses many characteristics of PrPSc including the ability to cause neurotoxicity in neuronal cells which catalyze the aggregation of endogenous PrPC to fibril accumulation $(13,14)$. These characteristics are useful for the in vitro study of PrPSc pathogenesis (15).

Some reports showed that cholesterol levels influence the progression of neurodegenerative diseases, including Alzheimer's and prion diseases (16-18). Published articles can be divided into those suggesting that cholesterol may hasten the onset of neurodegenerative disorders and those that, on 
the other hand, support the notion that cholesterol may play a protective role in neurodegenerative diseases $(16,17,19)$. Some studies in particular suggest that statins, cholesterol-lowering drugs, prevent neurodegenerative diseases, including prion diseases and Alzheimer's, and decrease PrPSc formation $(20,21)$. However, other research showed that most statins do not cross the blood-brain barrier, and that the clinical benefit of statins may be due to their cholesterol-independent effect on neurodegenerative disorders $(22,23)$. This observation may support the idea that cholesterol may have a protective effect against neurodegenerative diseases. Accordingly, a recent study suggested that increasing membrane cholesterol contents prevents mitochondrial disruptions in Alzheimer's disease $(19,24,25)$. The effect of cholesterol on PrPSc-mediated mitochondrial dysfunction however, has not been reported.

It has recently been shown that the protective effects of cholesterol on neurodegenerative diseases are related to the modulation of lipid microdomains in plasma membranes $(16,19)$. Indeed, depletion of cholesterol leads to instability of lipid rafts and gradual loss of synapses and dendritic spines $(26,27)$. In addition, it is known that changing the cholesterol level can redistribute membrane proteins in neurons (28); however, the effect of cholesterol on the redistribution of PrPC in plasma membranes has not been reported.

Thus, the present study focused on the influence of cholesterol-mediated redistribution of PrPC and the regulation of the $\operatorname{PrP}(106-126)$-induced mitochondrial apoptotic pathway in neuronal cells. Our research showed that neuronal cells exposed to cholesterol experienced decreased $\operatorname{PrP}(106-$ 126)-mediated neurotoxicity and a redistribution of PrPC to non-lipid rafts. The present results suggest that regulation of membrane cholesterol affects the translocation of PrPC, which consequently regulates $\operatorname{PrP}(106-126)$-induced neurotoxicity.

\section{Materials and methods}

Cell culture. A human neuroblastoma cell line (SH-SY5Y) was obtained from the American Type Culture collection (ATCC, Rockville, MD, USA). Cells were cultured in minimum essential medium (MEM; Hyclone Laboratories, Logan, UT, USA) that contained $10 \%$ fetal bovine serum (FBS; InvitrogenGibco, Grand Island, NY, USA) and gentamycin $(0.1 \mathrm{mg} / \mathrm{ml})$ in a humidified incubator maintained at $37^{\circ} \mathrm{C}$ and $5 \% \mathrm{CO}_{2}$.

$\operatorname{PrP}(106-126)$ treatment. Synthetic $\operatorname{PrP}(106-126)$ (sequence, Lys-Thr-Asn-Met-Lys-His-Met-Ala-Gly-Ala-Ala-Ala-Ala-GlyAla-Val-Val-Gly-Gly-Leu-Gly) were synthesized from Peptron (Seoul, Korea). The peptides were dissolved in sterile dimethyl sulfoxide (DMSO) at a $12.5 \mathrm{mM}$ concentration and stored at $-80^{\circ} \mathrm{C}$.

Annexin $V$ assay. Apoptosis was assessed by the Annexin V assay in the detached cells using an Annexin V assay kit (Santa Cruz Biotechnology) according to the manufacturer's protocol. Annexin $\mathrm{V}$ levels were determined by measuring fluorescence at $488 \mathrm{~nm}$ excitation and 525/30 emission using a Guava easyCyte HT System (Millipore).

Terminal deoxynucleotidyl transferase dUTP nick end labeling (TUNEL) assay. TUNEL analysis was performed to measure the degree of cellular apoptosis using an in situ Apo-BrdU DNA Fragmentation assay kit (BioVision, San Francisco, CA, USA) following the manufacturer's instructions. Cells were washed with phosphate-buffered saline (PBS) and fixed with paraformaldehyde for $15 \mathrm{~min}$ then pre-incubated with $50 \mu \mathrm{l}$ of DNA-labeling solution (10 $\mu 1 \mathrm{TdT}$ reaction buffer, $0.75 \mu 1 \mathrm{TdT}$ enzyme, $8 \mu \mathrm{l} \mathrm{Br}$-dUTP) for $1 \mathrm{~h}$ at $37^{\circ} \mathrm{C}$, then incubated with $5 \mu \mathrm{l}$ anti-BrdU-FITC antibody for $0.5 \mathrm{~h}$ at room temperature $\left(20^{\circ} \mathrm{C}\right)$. Finally, cells were mounted with DakoCytomation fluorescent medium and visualized using fluorescence microscopy. Cells were counterstained with propodium iodide (PI) to show all cell nuclei.

Western blot analyses. After SH-SY5Y cells were lysed in buffer (25 mM HEPES; pH 7.4, $100 \mathrm{mM} \mathrm{NaCl,} 1 \mathrm{mM}$ EDTA, $5 \mathrm{mM} \mathrm{MgCl}, 0.1 \mathrm{mM}$ DTT, and protease inhibitor mixture), proteins were electrophoretically resolved on a $10-15 \%$ sodium dodecyl sulfate (SDS) polyacrylamide gel, and transferred to a nitrocellulose membrane. Immunoreactivity was detected through sequential incubation with horseradish peroxidase-conjugated secondary antibodies and enhanced chemiluminescence (ECL) reagents. The antibodies used for immunoblotting were PrPc (Millipore), caveolin-1, caspase-3, and phospho-p38 (Cell Signaling Technology), phospho-Fyn (Abcam), Bax (Santa Cruz Biotechnology), cytochrome c (BD Biosciences) and $\beta$-actin (Sigma). Images were examined using a Fusion FX7 imaging system (Vilber Lourmat).

Isolation of detergent-resistant membranes (DRM). Cells were washed twice in Tris-buffered saline (25 mM Tris-Cl, $140 \mathrm{mM}$ $\mathrm{NaCl}, \mathrm{pH} 7.5$ ) then lysed in $1 \mathrm{ml}$ of lysis buffer (1\% Triton X-100, $25 \mathrm{mM}$ Tris-Cl, $140 \mathrm{mM} \mathrm{NaCl}, \mathrm{pH} 8.0$ and protease inhibitor mixture), fractionated on a bottom-loaded discontinuous sucrose gradient, and analyzed by Western blotting.

Cellular fractionation. SH-SY5Y cells were resuspended in mitochondrial buffer $(210 \mathrm{mM}$ sucrose, $70 \mathrm{mM}$ mannitol, $1 \mathrm{mM}$ EDTA, $10 \mathrm{mM}$ HEPES), broken by a 26-guage needle, and subjected to centrifugation at $700 \mathrm{x}$ g for $10 \mathrm{~min}$. The post nuclear supernatant was centrifuged at $10,000 \mathrm{x} g$ for $30 \mathrm{~min}$ at $4^{\circ} \mathrm{C}$. The pellet was used as the mitochondrial fraction and the supernatant was used as the cytosolic fraction. Total proteins were obtained and subjected to Western blotting.

Mitochondrial transmembrane potential (MTP) assay. The change in MTP was evaluated by the cationic fluorescent indicator JC-1 (Molecular Probes Eugene, OR, USA) which aggregates in intact mitochondria (red fluorescence) indicating high or normal MTP and low MTP when it remains in monomeric form in the cytoplasm (green fluorescent). SH-SY5Y cells were incubated in MEM containing $10 \mu \mathrm{M} \mathrm{JC}-1$ at $37^{\circ} \mathrm{C}$ for $15 \mathrm{~min}$, washed with PBS and lysed in buffer $(25 \mathrm{mM}$ HEPES pH 7.4; $100 \mathrm{mM} \mathrm{NaCl}, 1 \mathrm{mM}$ EDTA, $5 \mathrm{mM} \mathrm{MgCl}_{2}$, $0.1 \mathrm{mM}$ DTT, and protease inhibitor mixture), then transferred to a clear 96-well plate. J-aggregate fluorescent emission was measured at $595 \mathrm{~nm}$ with an excitation wavelength of $560 \mathrm{~nm}$, and JC-1 monomer fluorescence intensity was measured with excitation and emission at 485 and $535 \mathrm{~nm}$, respectively using a SpectraMax M2 (Molecular Devices). SH-SY5Y cells were cultured on coverslips in a 24-well plate, incubated in MEM 

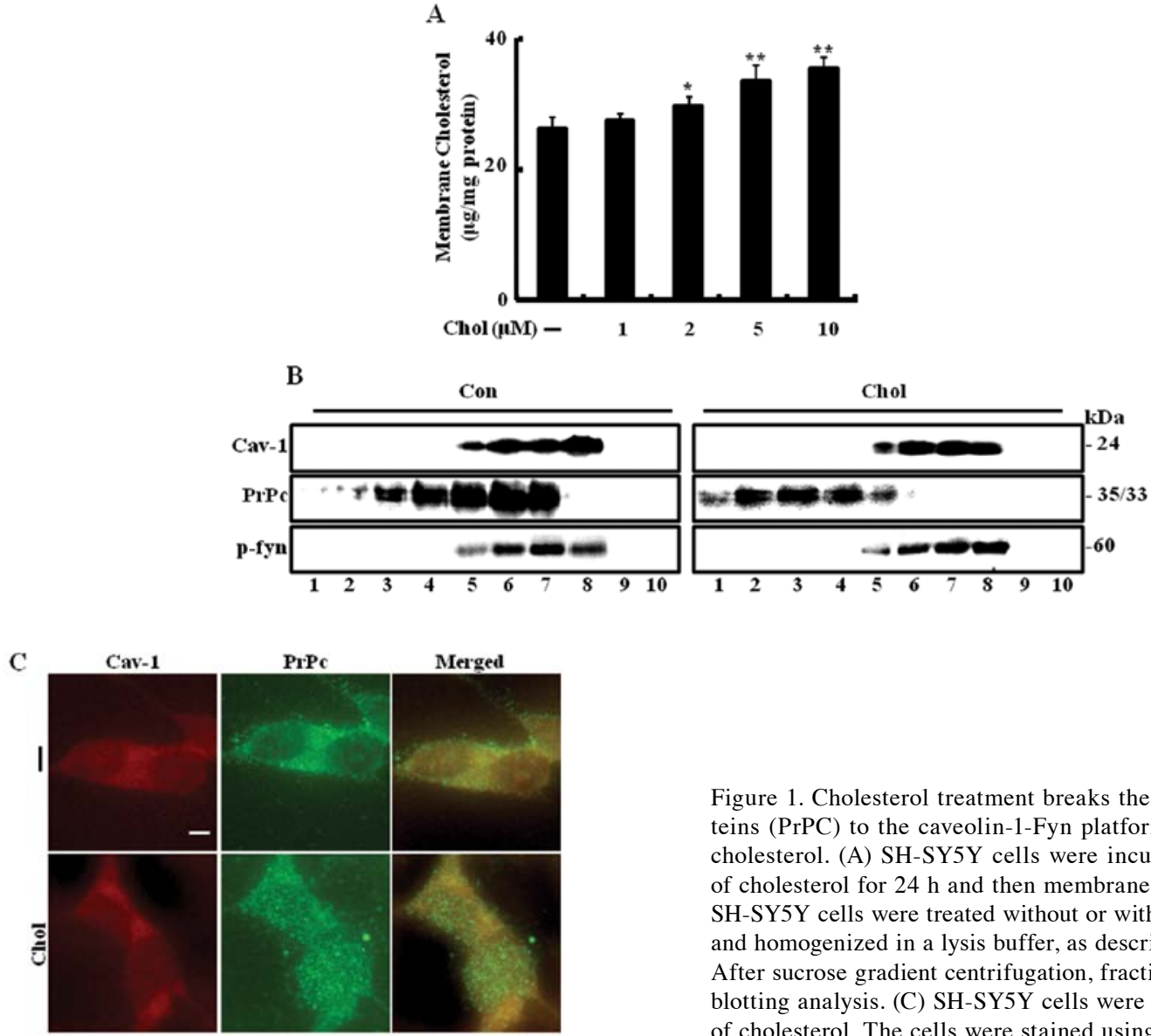

D

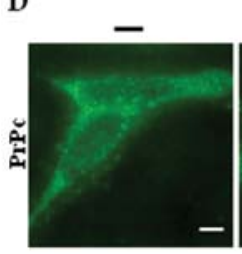

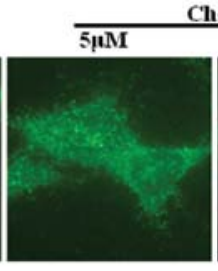
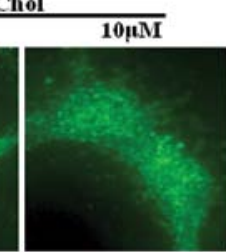

containing $10 \mu \mathrm{M} \mathrm{JC}-1$ at $37^{\circ} \mathrm{C}$ for 15 min then washed with PBS. Finally, cells were mounted with DakoCytomation fluorescent medium and visualized via fluorescence microscopy.

Immunofluorescence. Cell lines cultured on glass coverslips were treated with SFN (Sigma) and/or TRAIL, washed with PBS and fixed with cold acetone for $90 \mathrm{sec}$ at room temperature. Cells were then washed with PBS again, blocked with 5\% FBS in Tris-buffered saline with Tween (TBST), and incubated with anti-caveolin-1 $(2 \mu \mathrm{g} / \mathrm{ml})$ and anti-PrPc $(2 \mu \mathrm{g} / \mathrm{ml})$ monoclonal antibodies for $48 \mathrm{~h}$ at room temperature. Unbound antibody was removed by an additional PBS wash, after which cells were incubated with labeled anti-rabbit Alexa Fluor 546 (for anti-caveolin-1 and anti-PrPC) and IgG antibodies $(4 \mu \mathrm{g} / \mathrm{ml})$ for $2 \mathrm{~h}$ at room temperature. Finally, cells were mounted with DakoCytomation fluorescent medium and visualized via fluorescence microscopy.

Cholesterol and protein content. Cellular cholesterol and protein content were determined in cell extracts $\left(5 \times 10^{6}\right.$ cells $\left./ \mathrm{ml}\right)$. Protein concentrations were measured using a Micro $\mathrm{BCA}^{\mathrm{TM}}$
Figure 1. Cholesterol treatment breaks the linkage of cellular prion proteins (PrPC) to the caveolin-1-Fyn platform when cells are treated with cholesterol. (A) SH-SY5Y cells were incubated with the indicated dose of cholesterol for $24 \mathrm{~h}$ and then membrane cholesterol was extracted. (B) SH-SY5Y cells were treated without or with $10 \mu \mathrm{M}$ of cholesterol for $24 \mathrm{~h}$ and homogenized in a lysis buffer, as described in Materials and methods. After sucrose gradient centrifugation, fractions were subjected to Western blotting analysis. (C) SH-SY5Y cells were treated without or with $10 \mu \mathrm{M}$ of cholesterol. The cells were stained using anti-PrPc and anti-caveolin-1 antibodies, followed by confocal microscopy analysis. Scale bar, $10 \mu \mathrm{m}$. (D) SH-SY5Y cells were incubated with the indicated dose of cholesterol for $12 \mathrm{~h}$ and stained using anti-PrPc, followed by confocal microscopy analysis. Scale bar, $10 \mu \mathrm{m} .{ }^{*} \mathrm{P}<0.05,{ }^{* * *} \mathrm{P}<0.01$, significant differences between the control and each treatment group.

protein assay kit (Pierce). Cholesterol amounts were measured using the Amplex ${ }^{\circledR}$ Red Cholesterol assay kit (Invitrogen), according to the manufacturer's instructions. Briefly, cholesterol was oxidized by cholesterol oxidase to yield hydrogen peroxide and ketones. The hydrogen peroxide reacted with dihydroxyphenoxazine to produce highly fluorescent resorufin, which was measured at $550 \mathrm{~nm}$ excitation and $590 \mathrm{~nm}$ emission.

Statistical evaluation. All data are expressed as means \pm standard deviations (SD), and compared using the Student's t-test, ANOVA, and Duncan's test with the SAS statistical software. Results were considered significant at $\mathrm{P}<0.05$ or $\mathrm{P}<0.01$.

\section{Results}

Membrane cholesterol enrichments inhibits PrP(106-126)induced apoptotic signaling by translocation of $\operatorname{PrPC}$ to non-lipid rafts. Previously, we demonstrated that increasing cellular cholesterol levels prevents prion-mediated neurotoxicity. Because, PrPC-mediated Fyn signaling occurs in lipid rafts/ caveolae, and because we noticed redistribution of plasma 


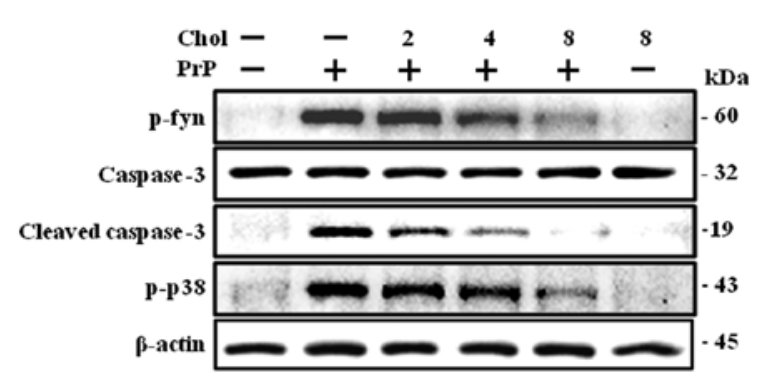

Figure 2. Effects of cholesterol treatment on the $\operatorname{PrP}(106-126)$-mediated neuronal apoptotic pathway. (A) SH-SY5Y cells were pretreated with cholesterol $(8 \mathrm{~h})$ in a dose-dependent manner and then exposed to $50 \mu \mathrm{M} \operatorname{PrP}(106-126)$ for $16 \mathrm{~h}$. Treated cells were assessed for p-Fyn, caspase-3, cleaved caspase-3, and p-p38 production by Western blot analysis. Results were normalized to $\beta$-actin.

membrane proteins following cholesterol treatment, in this study we further examined whether cholesterol had a preventative effect on prion-mediated neurotoxicity and whether it is associated with PrPC redistribution on plasma membranes. First, we checked membrane cholesterol levels after cholesterol treatment and found the levels to be dose-dependently increased in the cholesterol-treated group compared to that of the control group (Fig. 1A).

We then examined whether cholesterol treatment affects PrPC localization by immunostaining for PrPC and caveolin-1. Consistent with previous studies (10) showing that caveolin-1 is localized to focal adhesions, PrPC and caveolin-1 were co-localized to focal adhesion areas in the control cells (Fig. 1C). In contrast, PrPC appeared to distribute into the whole cell body while, caveolin-1 localization appeared to undergo no changes when cells were treated with cholesterol (Fig. 1C and D). The PrPC-caveolin-1-Fyn platform was also found in caveolae fractions, but levels of caveolae-associated PrPC-caveolin-1-Fyn platforms showed a break in the linkage of PrPC to the platform when cells were treated with cholesterol (Fig. 1B).

Activation of Fyn kinase is known to be responsible for neurotoxicity associated with prion infections. Thus, to determine whether cholesterol enrichment has an effect on the levels of Fyn, caspase-3 and p38 proteins, SH-SY5Y cells were pretreated with cholesterol in a dose-dependent manner, and then exposed to $\operatorname{PrP}(106-126)$. Prion peptide-treated cells had increased phosphorylated (p)-p38, p-Fyn, and cleaved caspase-3 protein levels (Fig. 2). In contrast, cholesterol administration was associated with decreased p-p38, p-Fyn, and cleaved caspase-3 protein levels in SH-SY5Y cells treated with $\operatorname{PrP}(106-126)$, in a dose-dependent manner (Fig. 2). Collectively, these results are consistent with the idea that cholesterol enrichment inhibits $\operatorname{PrP}(106-126)$-induced apoptotic pathways by regulation of PrPC distribution.

\footnotetext{
Administration of cholesterol inhibits $\operatorname{PrP}(106-126)$-induced neurotoxicity by regulating mitochondrial apoptotic pathways. Because mitochondrial dysfunction is known to be responsible for neurotoxicity associated with prion diseases, we investigated whether cholesterol enrichment had an effect on the mitochondrial apoptotic pathway. SH-SY5Y cells were preincubated with different concentrations of cholesterol for $12 \mathrm{~h}$ then exposed to $\operatorname{PrP}(106-126)$. After treatment with cholesterol
}

A

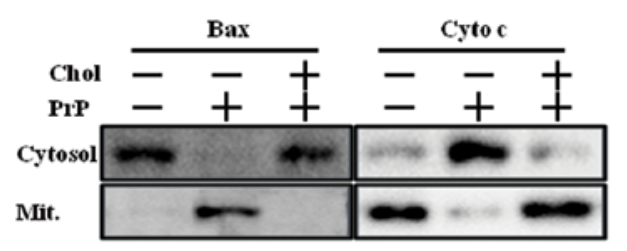

B

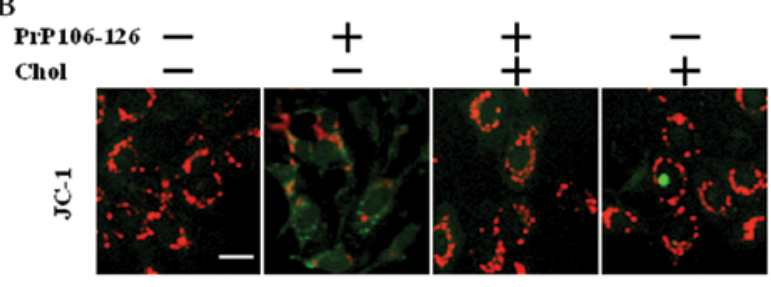

C

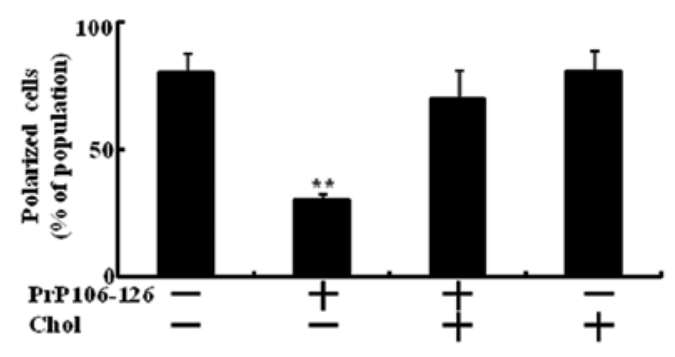

Figure 3. Membrane cholesterol enrichment inhibited PrP(106-126)-induced mitochondrial dysfunctions in neuronal cells. (A) SH-SY5Y cells were pretreated with $10 \mu \mathrm{M}$ of cholesterol ( $8 \mathrm{~h}$ ) and then exposed to $50 \mu \mathrm{M} \operatorname{PrP}(106-126)$ for $16 \mathrm{~h}$. The cells were homogenized in a mitochondrial buffer, as described in Materials and methods and the separated cytosol and mitochondrial extracts analyzed by Western blotting using antibodies against cytochrom $\mathrm{c}$ and Bax protein. (B) Cells were pretreated with $10 \mu \mathrm{M}$ of cholesterol ( $8 \mathrm{~h}$ ) and then exposed to $50 \mu \mathrm{M} \operatorname{PrP}(106-126)$ for $16 \mathrm{~h}$. JC-1 aggregate form (red) and mono form (green) were measured in the treated cells by confocal microscopy analysis. Scale bar, $50 \mu \mathrm{m}$. (C) Bar graph indicates the averages of JC-1 aggregate positive cells and shows mean \pm standard error of the mean (SEM; $n=3$ ). ${ }^{* *} \mathrm{P}<0.01$, significant differences between control and each treatment group.

and $\operatorname{PrP}(106-126)$, cytosolic and mitochondrial fractions were prepared as described in Materials and methods and subjected to Western blot analysis. $\operatorname{PrP}(106-126)$ translocated Bax protein from the cytosol to the mitochondria and released cytochrome $\mathrm{c}$ from the mitochondria to the cytosol (Fig. 3A). In contrast, cholesterol treatment inhibited $\operatorname{PrP}(106-126)$-induced Bax translocation and cytochrome c release in SH-SY5Y cells. We also examined the effect of cholesterol enrichment on MTP (Fig. 3B and C). SH-SY5Y cells were pretreated with cholesterol for $12 \mathrm{~h}$ then exposed to $\operatorname{PrP}(106-126)$. Results of fluorescence microscopy analysis presented in Fig. 3B show cells with green fluorescence after $\operatorname{PrP}(106-126)$ treatment indicating lower MTP, while the negative control cells and $\operatorname{PrP}(106-126)$-treated cells show red fluorescence, indicating high MTP values (Fig. 3B and C).

The influence of cholesterol enrichment on $\operatorname{PrP}(106-126)-$ induced apoptosis in SH-SY5Y cells was estimated by the Annexin $\mathrm{V}$ assay. Cells were exposed to cholesterol with or without PrP(106-126). Treatment of SH-SY5Y cells with $\operatorname{PrP}(106-126)$, but not cholesterol, resulted in neurotoxicity, identified by the fact that Annexin $\mathrm{V}$ positive cells were increased $52.46 \%$ after $24 \mathrm{~h}$ (Fig. 4A and B). However, cholesterol treatment inhibited $\operatorname{PrP}(106-126)$-induced apoptosis (Fig. 4A and B). These results were confirmed by a TUNEL assay (Fig. 4C) and suggest that cholesterol 

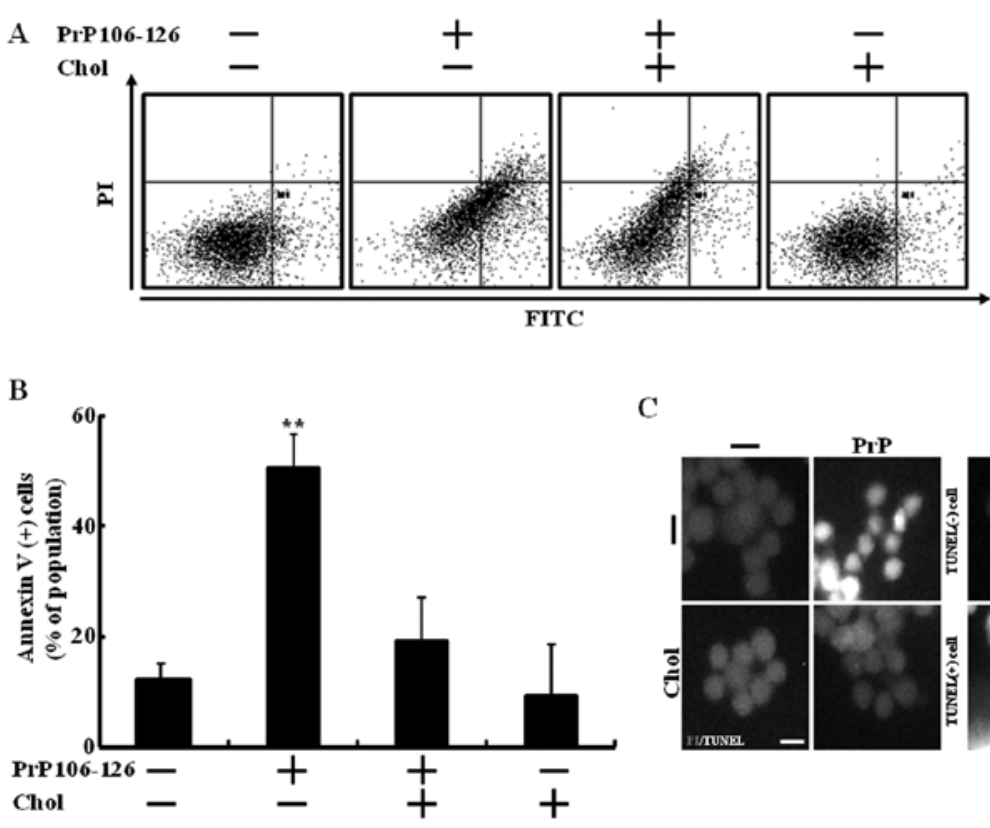

$\mathrm{C}$

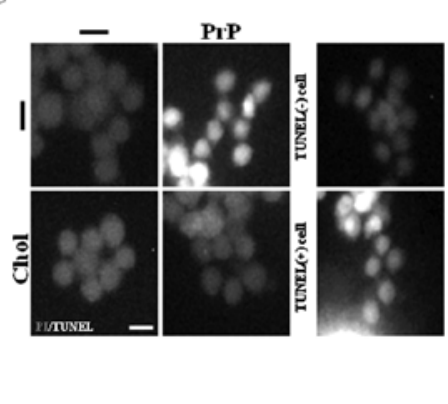

Figure 4. Membrane cholesterol enrichment protected against $\operatorname{PrP}(106-126)$-induced neurotoxicity. (A) SH-SY5Y cells were pretreated with $10 \mu \mathrm{M}$ of cholesterol $(8 \mathrm{~h})$ and then exposed to $50 \mu \mathrm{M} \operatorname{PrP}(106-126)$ for $16 \mathrm{~h}$. Cell viability was measured by Annexin $\mathrm{V}$ assay. (B) Bar graph indicates the averages of Annexin V positive cells and the mean \pm SEM $(n=3)$. ${ }^{* *} \mathrm{P}<0.01$, significant differences between control and each treatment group. (C) Representative immunofluorescence images of TUNEL-positive SH-SY5Y cells $8 \mathrm{~h}$ after exposure to $50 \mu \mathrm{M}$ of $\operatorname{PrP}(106-126)$ in the absence or presence of cholesterol. Cells were counterstained with propodium iodide to show all cell nuclei. Magnification, x400; scale bar, $100 \mu \mathrm{m}$.

enrichment attenuates $\operatorname{PrP}(106-126)$-induced apoptosis in SH-SY5Y cells.

\section{Discussion}

The purpose of this study was to investigate the role of membrane cholesterol enrichment in $\operatorname{PrP}(106-126)$-induced mitochondrial apoptotic signaling and the influence of increased cholesterol in PrPC-caveolin-1-Fyn signaling.

The prion protein fragment, $\operatorname{PrP}(106-126)$, serves as a suitable model of PrPSc neurotoxicity because it possesses many properties of the pathogenic PrPSc. PrPSc or PrP(106-126) are known to induce neurotoxicity through increasing p-Fyn, activated caspase-3, and p-p38 protein levels. Consistent with this knowledge, PrP(106-126) treatment of SH-SY5Y cells increased p-Fyn, activated caspase-3, and p-p38 protein levels (Fig. 2).

Some studies have suggested that regulation of cholesterol levels influences the progression of neurodegenerative diseases including Alzheimer's and prion diseases (17-19). Kempster et al (18) suggested that decreasing cholesterol levels using statins prevents PrPSc-induced neuronal cell death. Other studies showed that most of the statins do not cross the blood-brain barrier, although statin therapy may provide protection against neurodegenerative diseases such as Alzheimer's $(22,23)$. This observation may suggest that the clinical benefit of statins on neurodegenerative diseases may not be related to the reduction of cholesterol. Also, a recent study suggested that increasing membrane cholesterol prevents A $\beta$-induced oxidative stress through modulation of membrane cholesterol in Alzheimer's disease (19). Consistent with this information, the $\operatorname{PrP}(106-126)$-induced elevation of p-Fyn, activated caspase-3, and p-p38 protein levels were reduced by increasing membrane cholesterol using water-soluble cholesterol treatment (Fig. 2). Taken together, these data suggest that membrane cholesterol enrichment protects against prioninduced neurotoxicity through regulation of p-Fyn, activated caspase-3, and p-p38 protein levels.

PrPC/caveolin-1/Fyn signaling is known to be responsible for prion-mediated neurotoxicity $(29,30)$. Some reports showed that inhibition of Fyn kinase activation in PrPC knock-out cells was blocked by $\operatorname{PrP}(106-126)$-induced PrPC/caveolin-1/Fyn signaling and prevented PrPSc-mediated neuronal cell death $(19,30)$. This observation may suggest that regulation of the PrPC/caveolin-1/Fyn platform may be a therapeutic strategy for neurodegenerative diseases including prion diseases. Also, recent studies suggested that modulation of cholesterol regulates distribution of lipid microdomain proteins in plasma membranes (28). Consistent with this information, cells treated with cholesterol had a break in the linkage of PrPC to the caveolin-1-Fyn platform, although activated-Fyn was not changed with regard to linkage to caveolin-1 (Fig. 1B and C). Thus, this observation supports the hypothesis that increasing membrane cholesterol prevents PrP-mediated apoptosis by inhibition of PrPC/caveolin-1/Fyn kinase signaling by breaking the linkage between PrPC and the caveolin-1/Fyn platform.

The mitochondrial apoptotic pathway is thought to play an important role in neurodegenerative diseases and to be related to activation of Fyn kinase signaling (31). A recent study showed that increasing membrane cholesterol prevents oxidative stress in Alzheimer's disease (19). Also, some reports suggested that PrPSc-induced neurotoxicity is blocked by inhibition of mitochondrial apoptotic pathways (10-12). Our data showed that $\operatorname{PrP}(106-126)$ decreased MTP and translocated Bax protein from the cytosol to the mitochondria and the release of cytochrome $\mathrm{c}$ from the mitochondria to the cytosol 
was blocked in cells exposed to cholesterol (Fig. 3). Thus these observations support the hypothesis that membrane cholesterol enrichment protects against PrP-mediated apoptosis by inhibition of mitochondrial apoptotic pathways.

Taken together, these results demonstrate that membrane cholesterol enrichment decreased $\operatorname{PrP}(106-126)$-induced neuronal cell death and $\operatorname{PrP}(106-126)$-mediated mitochondrial dysfunction by regulation of PrPC/caveolin-1/Fyn signaling. Furthermore, these research approaches will contribute to the understanding of the role of membrane cholesterol in neurodegenerative diseases including prion disease.

\section{Acknowledgements}

This study was supported by a grant from the Regional Research Universities Program and the Center for Healthcare Technology Development and the National Research Foundation of Korea funded by the Korean Government (2011-0026603).

\section{References}

1. Brandner S, Klein MA, Frigg R, et al: Neuroinvasion of prions: insights from mouse models. Exp Physiol 85: 705-712, 2000.

2. Kretzschmar HA: Molecular pathogenesis of prion diseases. Eur Arch Psychiatry Clin Neurosci 249 (Suppl 3): S56-S63, 1999.

3. Avrahami D and Gabizon R: Age-related alterations affect the susceptibility of mice to prion infection. Neurobiol Aging 32: 2006-2015, 2009.

4. Diez M, Groth D, DeArmond SJ, Prusiner SB and Hokfelt T: Changes in neuropeptide expression in mice infected with prions. Neurobiol Aging 28: 748-765, 2007.

5. Bate C, Tayebi $M$ and Williams A: The glycosylphosphatidylinositol anchor is a major determinant of prion binding and replication. Biochem J 428: 95-101, 2010.

6. Tomasi V: Signal transduction in neurons: effects of cellular prion protein on fyn kinase and ERK1/2 kinase. Immun Ageing 7 (Suppl 1): S5, 2010.

7. Lewis V and Hooper NM: The role of lipid rafts in prion protein biology. Front Biosci 16: 151-168, 2011.

8. Bate C and Williams A: Monoacylated cellular prion protein modifies cell membranes, inhibits cell signaling, and reduces prion formation. J Biol Chem 286: 8752-8758, 2011.

9. Radford HE and Mallucci GR: The role of GPI-anchored PrP C in mediating the neurotoxic effect of scrapie prions in neurons. Curr Issues Mol Biol 12: 119-127, 2010.

10. Pietri M, Caprini A, Mouillet-Richard S, et al: Overstimulation of PrPC signaling pathways by prion peptide 106-126 causes oxidative injury of bioaminergic neuronal cells. J Biol Chem 281: 28470-28479, 2006.

11. Bourteele S, Oesterle K, Weinzierl AO, et al: Alteration of NF-kappaB activity leads to mitochondrial apoptosis after infection with pathological prion protein. Cell Microbiol 9: 2202-2217, 2007.

12. Park JH, Kim BH, Park SJ, et al: Association of endothelial nitric oxide synthase and mitochondrial dysfunction in the hippocampus of scrapie-infected mice. Hippocampus 21: 319-333, 2011.
13. Gu Y, Fujioka H, Mishra RS, Li R and Singh N: Prion peptide 106-126 modulates the aggregation of cellular prion protein and induces the synthesis of potentially neurotoxic transmembrane PrP. J Biol Chem 277: 2275-2286, 2002.

14. Forloni G, Angeretti N, Chiesa R, et al: Neurotoxicity of a prion protein fragment. Nature 362: 543-546, 1993.

15. Singh N, Gu Y, Bose S, Kalepu S, Mishra RS and Verghese S: Prion peptide 106-126 as a model for prion replication and neurotoxicity. Front Biosci 7: a60-a71, 2002.

16. Stefani M and Liguri G: Cholesterol in Alzheimer's disease: unresolved questions. Curr Alzheimer Res 6: 15-29, 2009.

17. Jeong JK, Seol JW, Moon MH, et al: Cellular cholesterol enrichment prevents prion peptide-induced neuron cell damages. Biochem Biophys Res Commun 401: 516-520, 2010.

18. Kempster S, Bate C and Williams A: Simvastatin treatment prolongs the survival of scrapie-infected mice. Neuroreport 18: 479-482, 2007.

19. Pensalfini A, Zampagni M, Liguri G, et al: Membrane cholesterol enrichment prevents Abeta-induced oxidative stress in Alzheimer's fibroblasts. Neurobiol Aging 32: 210-222, 2011.

20. Bate C, Rumbold L and Williams A: Cholesterol synthesis inhibitors protect against platelet-activating factor-induced neuronal damage. J Neuroinflammation 4: 5, 2007.

21. Tong XK, Nicolakakis N,Fernandes P, et al: Simvastatin improves cerebrovascular function and counters soluble amyloid-beta, inflammation and oxidative stress in aged APP mice. Neurobiol Dis 35: 406-414, 2009.

22. Fonseca AC, Proenca T, Resende R, Oliveira CR and Pereira CM: Neuroprotective effects of statins in an in vitro model of Alzheimer's disease. J Alzheimers Dis 17: 503-517, 2009.

23. Vuletic S, Riekse RG, Marcovina SM, Peskind ER, Hazzard WR and Albers JJ: Statins of different brain penetrability differentially affect CSF PLTP activity. Dement Geriatr Cogn Disord 22: 392-398, 2006.

24. Vargas T, Ugalde C, Spuch C, et al: A $\beta$ accumulation in choroid plexus is associated with mitochondrial-induced apoptosis. Neurobiol Aging 31: 1569-1581, 2010.

25. Imam SZ, Karahalil B, Hogue BA, Souza-Pinto NC and Bohr VA: Mitochondrial and nuclear DNA-repair capacity of various brain regions in mouse is altered in an age-dependent manner. Neurobiol Aging 27: 1129-1136, 2006.

26. Kannan M, Steinert JR, Forsythe ID, Smith AG and Chernova T: Mevastatin accelerates loss of synaptic proteins and neurite degeneration in aging cortical neurons in a heme-independent manner. Neurobiol Aging 31: 1543-1553, 2010.

27. Hering $\mathrm{H}$, Lin CC and Sheng M: Lipid rafts in the maintenance of synapses, dendritic spines, and surface AMPA receptor stability. J Neurosci 23: 3262-3271, 2003.

28. Taghibiglou C, Bradley CA, Gaertner T, Li Y, Wang Y and Wang YT: Mechanisms involved in cholesterol-induced neuronal insulin resistance. Neuropharmacology 57: 268-276, 2009.

29. Bizat N, Peyrin JM, Haik S, et al: Neuron dysfunction is induced by prion protein with an insertional mutation via a Fyn kinase and reversed by sirtuin activation in Caenorhabditis elegans. $\mathrm{J}$ Neurosci 30: 5394-5403, 2010.

30. Didonna A and Legname G: Aberrant ERK 1/2 complex activation and localization in scrapie-infected GT1-1 cells. Mol Neurodegener 5: 29, 2010.

31. Crews L and Masliah E: Molecular mechanisms of neurodegeneration in Alzheimer's disease. Hum Mol Genet 19: R12-R20, 2010. 